and the paranuclein are calculated free from phosphoric acid, $\mathrm{H}_{3} \mathrm{PO}_{4}$, possibly identical with "paranucleic acid", the composition found for the organic part of all of these preparations is so nearly the same as to show that the proteid and the nuclein are both compounds of one and the same proteid body, vitellin, with a phosphoric acid, possibly $\mathrm{H}_{3} \mathrm{PO}_{4}, \mathrm{H}_{2} \mathrm{P}_{2} \mathrm{O}_{9}$, or some very simple organo-phosphoric acid. The composition of the organic part of the preparations calculated free from $\mathrm{H}_{3} \mathrm{PO}$, gives as the average for eight preparations of the paranucleoproteid and the paranuclein, the following figures:

COMPOSITION OF VITELIIN.

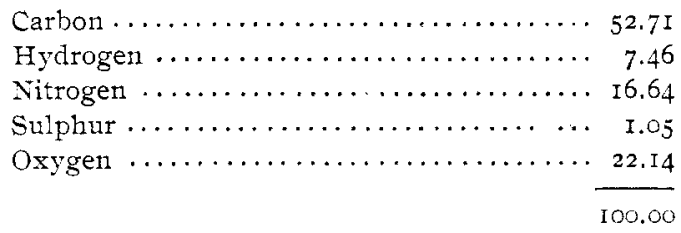

\title{
THE PROTEIN CONSTITUENTS OF EGG WHITE.'
}

By ThoMas B. OSBORNE AND GeORGE F. CAMPBELL

Received June :6, 1900.

$A$ RECENT paper by the writer ${ }^{2}$ gave an account of prepara$A$ tions of crystallized egg albumin which justified the conclusion that with the substance commonly called ovalbumin there is associated one or more other protein bodies, the properties of which were not definitely ascertained.

We have since repeated this work on a larger scale and have not only confirmed the former observations, but have obtained much additional information respecting these other protein bodies.

FRACTIONAL PRECIPITATION OF EGG WHITE.

Six liters of the whites of freshly laid eggs were gradually and carefully mixed with an equal volume of saturated ammonium sulphate solution and formed the precipitate, $A$, which was filtered off.

To the filtrate saturated ammonium sulphate solution was

1 From advance sheets of the report of the Connecticut Agricultural Experiment Station for 1899 , communicated by the authors.

2 Report Conn. Agr. Exp. Station for 1898 , and this Journal, $21,486$. 
added until a small permanent precipitate was produced, and then a mixture of $600 \mathrm{cc}$. of saturated ammonium sulphate solution, $830 \mathrm{cc}$. of water, and $27 \mathrm{cc}$. of concentrated hydrochloric acid were gradually added. After standing over night, the large quantity of fine needle-shaped crystals which separated, fraction $B$, was filtered out.

The filtrate, mixed with saturated ammonium sulphate solution. until a small precipitate again formed, was allowed to stand over night, during which time another crystalline precipitate, C, separated.

By treating the filtrate from $C$ in the same manner, another precipitate, D, was obtained, which consisted wholly of spheroids.

All the protein matter which remained in the filtrate from $D$ was precipitated by saturating the solution with ammonium sulphate, and this made preparation $\mathrm{E}$. These several fractions were then further divided as follows:

Precipitate $A$ was treated with water, strained with difficulty, owing to its gummy character, through bolting-cloth, and the slightly turbid solution thus obtained was dialyzed for several days. The considerable mucin-like precipitate which separated was filtered out, washed with much water, and dehydrated with absolute alcohol, giving 26.88 grams of preparation A.r.a.

The filtrate from the precipitate of A.I.a., saturated with ammonium sulphate, yielded a precipitate which was treated with a little water, and the part insoluble therein filtered out; the filtrate was allowed to evaporate until an amorphous precipitate separated. This precipitate was filtered out, united with the insoluble part of the ammonium sulphate precipitate, dissolved in water, and its solution dialyzed, yielding a precipitate which resembled that previously obtained by dialysis, being largely composed of gummy, mucin-like clots. This, when well washed with water and alcohol and dried, gave 7.28 grams of A.r.b. The dialyzed solution from which A.I.b had separated, when treated with ammonium sulphate, yielded a precipitate which was filtered out, pressed on filter-paper, dissolved in water and this solution dialyzed free from sulphate. This dialyzed solution, evaporated at $40^{\circ}$, left a residue, marked A.2, weighing, dry, I6 grams. 
The solution containing sulphate of ammonium, from which had been separated the substance yielding the two last-named preparations, was further concentrated by gradual evaporation, and yielded a mass of needle-shaped crystals. These were separated by filtration, dissolved in water, the solution was dialyzed till free from ammonium sulphate and evaporated at $40^{\circ}$, giving preparation A.3, weighing $11.5^{6}$ grams.

Precipitate B.-This, consisting wholly of well-formed crystals, was dissolved in water and treated with saturated ammonium sulphate solution, which was added until precipitation began. After standing over night, the wholly crystalline precipitate was filtered out and the filtrate, marked b.2, treated as will be described later. The precipitate was again dissolved in water and enough ammonium sulphate added to give a precipitate from which, after a time, the solution was decanted. After pressing ont the mother-liquor, the precipitate was dissolved in water and the clear solution dialyzed until wholly free from sulphate, when it was evaporated at $50^{\circ}$, giving 36 grams of B.I.

The filtrate from the precipitation of $B$.I treated with more ammonium sulphate, on standing twelve hours, deposited a large crop of finely developed crystals. This was filtered out and, treated in the manner described for B.I, gave 59 grams of B.2. The filtrate from B. 2 was added to solution b. 2 .

Precipitate C.-The filtrates from B. I and B.2, forming solution b.2, were united with the aqueous solution of fraction $C$, ammonium sulphate was added to incipient precipitation and the mixture was allowed to stand over night. The substance, which separated in spheroids, was filtered out, dissolved in water and recrystallized by adding ammonium sulphate. On standing, the substance deposited in large aggregates of crystals, extending from the bottom of the dish in warty masses, some of them more than $2 \mathrm{~cm}$. long and $0.5 \mathrm{~cm}$. in diameter. These masses were wholly composed of exceptionally large and well-formed needle crystals. After separating from the mother-liquor, this crystalline mass was dissolved in water and the solution dialyzed till free from sulphate, and, evaporated at $50^{\circ}$, gave 45 grams of C.I.

The filtrate from C.I, on standing, yielded a very large quantity of substance which was composed almost wholly of crystals, only a very few spheroids being detected among them. This 
precipitate, by the treatment applied to C.I, yielded 106 grams of C.2.

The filtrate from the first precipitation of C.I was treated with more ammonium sulphate, the filtrate from C.2 was added, and the mixture allowed to evaporate slowly until a precipitate separated, which consisted of a mixture of crystals and spheroids. This yielded C.3, weighing 32.5 grams.

Precipitate D.-This was dissolved in water, ammonium sulphate solution was added and the mixture allowed to stand until a considerable separation of spheroids occurred, which, on settling, formed a clear, transparent deposit on the bottom of the dish.

After several reprecipitations, always without obtaining crystals, and thinking that the absence of crystals might be due to a deficiency of acid, we added to the solution $3 \mathrm{cc}$. of concentrated hydrochloric acid mixed with much ammonium sulphate solution. On standing, however, this solution, as before, deposited only spheroids. The deposit, after decanting the solution, was dissolved in water and its solution, after adding ammonium sulphate to incipient precipitation, was allowed to evaporate slowly. When considerable deposit had formed, the solution was decanted and allowed to concentrate until nearly all the remaining proteid matter had formed a coherent deposit of spheroids. These two deposits were each separately dissolved in water, their solutions dialyzed free from ammonium sulphate and evaporated to dryness at $50^{\circ}$, thus giving D. I, weighing $3 \circ$ grams and D.2, weighing 20 grams.

The solution, decanted from the first precipitate which separated after adding acid, gave on evaporation a precipitate consisting wholly of spheroids, which formed D.3, weighing 55 grams. The solution from this, on further concentration, deposited nearly all the dissolved protein in the form of spheroids, which, by the usual treatment, gave Io grams of D.4.

Precipitate E.-This, when dissolved in water, yielded a brilliant yellow solution, slightly acid to litmus. Thereto saturated ammonium sulphate solution, containing I cc. of concentrated hydrochloric acid, was added, which, on standing, caused a precipitate. This was filtered off, dissolved in water, ammonium sulphate was added to incipient precipitation, and after standing 
seven days, the deposit of spheroids which had separated was filtered out, yielding 6.2 grams of E.I. The filtrate contained no protein matter.

The filtrate from the first reprecipitation of $\mathrm{E}$ was mixed with ammonium sulphate until a considerable amorphous precipitate had formed. This was filtered out, dissolved in water, and after adding ammonium sulphate and allowing the solution to stand six days, it gave a precipitate of spheroids which yielded E..2, weighing 15.65 grams.

The solution decanted from the first precipitation of E.2, after evaporating for six days, gave a deposit of spheroids mixed with a little amorphous matter, which was marked $\mathrm{E} .3$, and weighed 22.5 grams.

We thus obtained from 6 liters of egg white, seventeen different fractions, containing 504 grams of substance, 262 grams of which were wholly crystalline, and since at least one-half of C. 3 consisted of crystals, the total amount of crystalline matter was 278 grams. Evidently more than one-half the protein constituents of egg white can be crystallized. The yield of crystallized albumin was about the same as that obtained by the writer in his previous investigation, being about 4.4 grams of crystallized albumin per $100 \mathrm{cc}$. of egg white, as against 5.3 and 4.9 grams previously obtained.

Fractions E.2 and E.3.-Since the fractions E.2 and E.3 appeared, by their behavior on heating with water, to contain at least three protein substances, the greater part of each preparation was treated with water. E.2 contained some matter insoluble in water which could not be filtered out, while E.3 gave a clear solution. Both solutions, heated in a water-bath, gave a flocculent coagulum at $58^{\circ}$ which, even after heating at $65^{\circ}$ for some time, could not be filtered out. The temperature was therefore raised to $72^{\circ}$ and held there some time, which caused more coagulum to separate in both solutions, but as the solutions could not even then be filtered, the bath was heated to boiling. With the rising temperature the coagulum rapidly increased, so that it could soon be filtered out on cloth. After thoroughly washing each coagulum with hot water and alcohol and drying over sulphuric acid, we obtained preparations E.2.a, weighing 6 grams, and E.3.a, weighing 8.6 grams. The clear, bright, 
yellow filtrates from these were united and poured into several volumes of alcohol, which threw out a white precipitate and held the yellow coloring-matter in solution.

The precipitate, E.4, washed with alcohol and ether and dried over sulphuric acid, weighed 5 grams.

These preparations were then dried to constant weight at $110^{\circ}$ and analyzed.

The heat coagulation points of their solutions, containing 2.5 per cent. of the protein substance and io per cent. of sodium chloride, were determined by gradually heating in a water-bath. In Table $\mathrm{I}$, page $428, T$ indicates the temperature at which the solution first became turbid, and $F$ that at which flocks separated.

The specific rotation was determined with a Schmidt and Haensch polarimeter, the readings on the sugar scale being converted into degrees of circular polarization by multiplying by 0.346 .

In the table the percentages of nitrogen marked $\mathrm{K}$, were found by the Kjeldahl process, those marked $A$, by the Dumas or absolute method.

These results entirely confirm those given in our former paper, but in consequence of the more extended series of fractional precipitations in the work now under discussion we have plainer evidence of the presence of the several protein constituents of the egg white.

Of these fractions, B.1, B.2, C.I, and C.2 consist of ovalbumin, separated in a completely crystalline condition, and, with the exception of a trace present in C.2, are wholly free from the lower coagulating albumin, thus demonstrating this latter to be a distinct substance. The rotation and elementary composition of these fractions are essentially the same as that given in our former paper for similar products.

In fraction E.4 we have ovomucoid not coagulated by heat, with a specific rotation of $61.5^{\circ}$ and of the same composition as Möner ${ }^{1}$ and $Z$ anetti ${ }^{2}$ found for this substance. The successive fractions, from C.3 to E.3.a inclusive, all have a higher specific rotation and contain a relatively considerable amount of an albumin coagulating at a much lower temperature than ovalbumin.

1 Zischr. physiol. Chem., 18, 525.

2 Ann. di Chim. e Farmac., No. 12, 1897. 


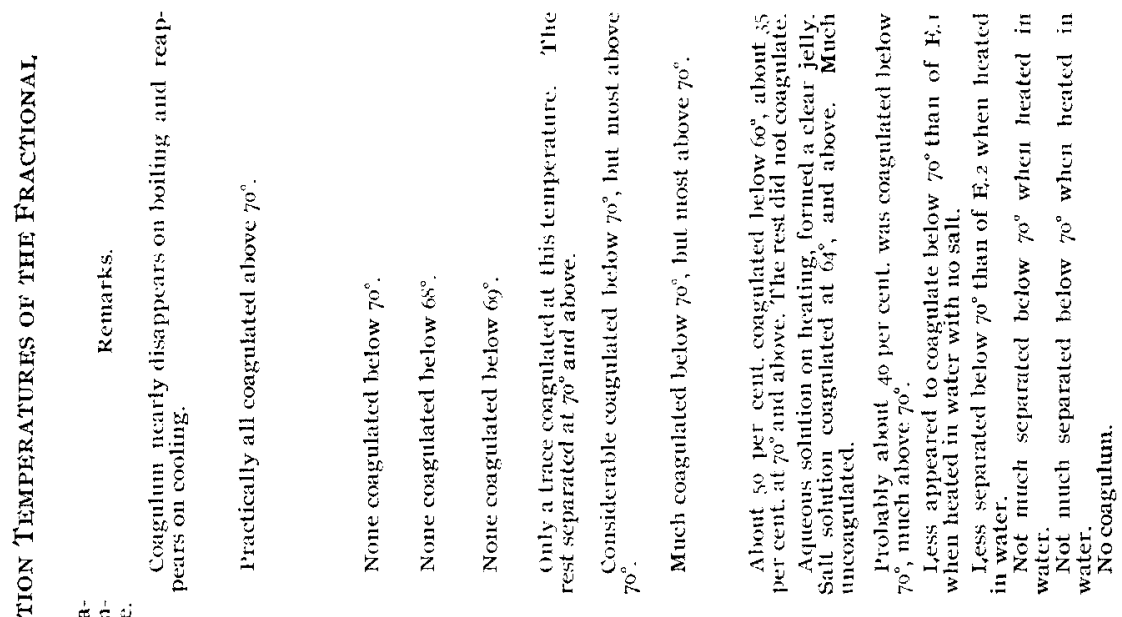

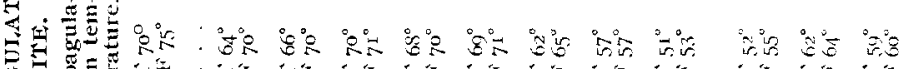

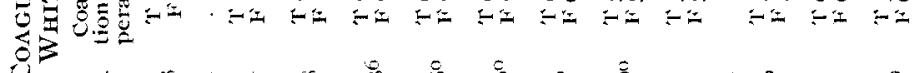

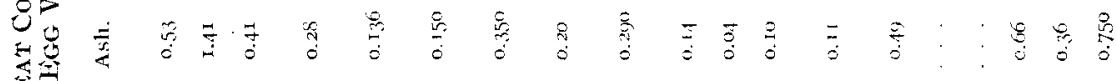

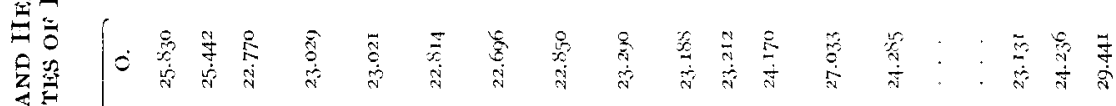

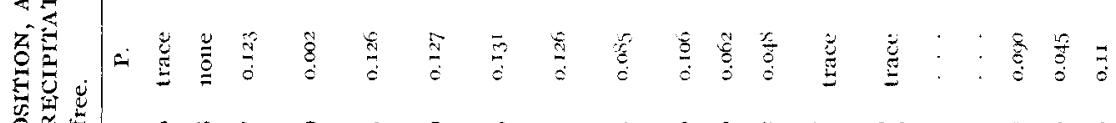

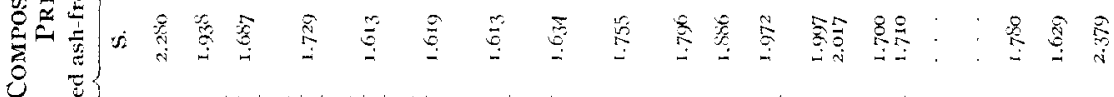

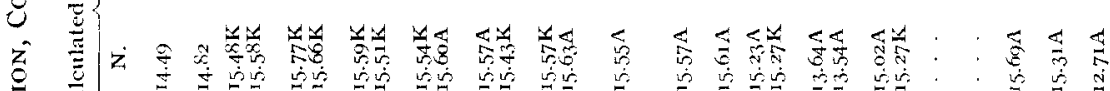

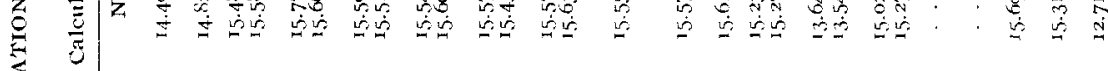

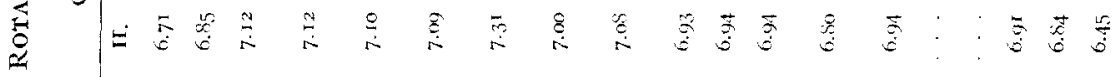

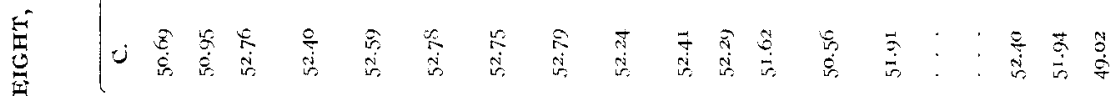

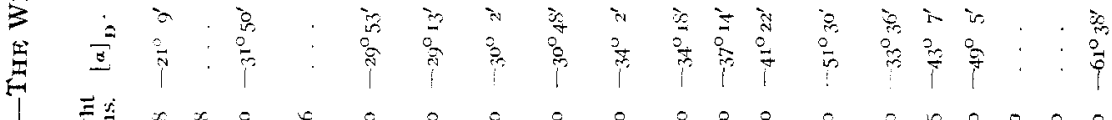

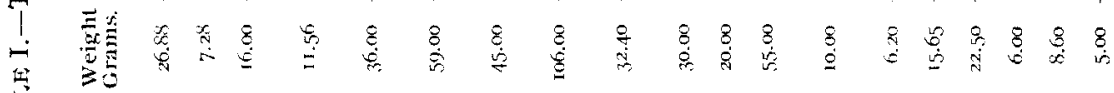

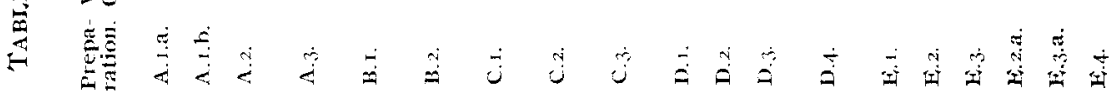


The fractions C.3, D.I, and D. 2 have nearly the same rotation temperatures of coagulation and composition. We therefore subjected these to fractional precipitation, in order to determine whether they were mixtures of different proteids or were essentially one substance. The greater parts of these preparations were accordingly united, dissolved in about $400 \mathrm{cc}$. of water and saturated ammonium sulphate solution added, until a decided precipitate had formed. This was filtered out, freed from mother-liquor, dissolved in water, the solution dialyzed until free from ammonium sulphate and then evaporated to dryness below $50^{\circ}$. The residue, F.I, weighed 7.5 grams. The filtrate from F.I, on evaporating at the room temperature, deposited a quantity of spheroids, mixed with a few crystals of ovalbumin. This deposit was filtered out, dissolved in water, to the solution saturated ammonium sulphate solution was added until incipient precipitation set in, and the whole was allowed to stand until a considerable precipitate composed of spheroids mixed with a few crystals had formed. This was filtered out and, in order, if possible, to convert the whole into crystals, the original reaction of the egg white was imitated by making the aqueous solution of the precipitate slightly alkaline with ammonia. A very small excess of hydrochloric acid was added and then ammonium sulphate to incipient precipitation, thus reproducing, as closely as we could, the conditions under which the first crystalline separation had been obtained. After standing, a precipitate formed which contained no crystals. This was filtered out and, by the usual treatment, gave F.2, weighing I 8.32 grams. The solutions filtered from the two preceding precipitations of F.2 were saturated with ammonium sulphate, and the resulting precipitate dissolved in water; its solution, dialyzed and evaporated below $50^{\circ}$, gave F.2.a, weighing 7.83 grams. The filtrate from the first precipitation of F.2 on further evaporation gave a precipitate of spheroids which was dissolved in water, and by the treatment employed for separating F.2.a, gave 16.7 grams of F.3.

The solution filtered from the second precipitation of F.3 was saturated with ammonium sulphate and from the precipitate produced by the usual treatment, F.3.a, weighing $5.3^{8}$ grams, was obtained. These several preparations were found to have the 
rotation, heat-coagulation temperatures and compositions gicen in Table II.

While none of these fractions was obtained free from the lower coagulating albumin, the relative proportions of the two albumins which the different fractions contained varied greatly, which fact, in conjunction with their rotation and composition, shows that a decided, though incomplete, separation has been effected.

In order to separate more completely the proteids which these mixed fractions appeared to contain, we dissolved I 3.4 grams of D.3 in $500 \mathrm{cc}$. of Io per cent. brine, and heated the filtered and perfectly clear solution slowly in a large water-bath. A flocculent coagulum began to separate at $52^{\circ}$, which, after heating for some time at $60^{\circ}$, was filtered off. The filtrate was then removed and this coagulum was washed with pure water, which, after the salt was removed, dissolved the coagulum almost completely. From these washings the proteid was separated by adding alcohol. When dried over sulphuric acid it weighed 5 grams and formed preparation D.3.I.

The solution filtered from the coagulum separating below $60^{\circ}$, when further heated, became turbid at $64^{\circ}$ and yielded a flocculent coagulum at $70^{\circ}$. This second coagulum was filtered off after heating for some time at $88^{\circ}$ and when washed and dried gave 3.5 grams of D.3.2. The filtrate from this gave no more coagulum on heating and after dialyzing free from chlorides was concentrated to small volume and precipitated by pouring into alcohol. This gave us 2 grams of D.3.3.

Seven grams of F.3 were dissolved in $280 \mathrm{cc}$. of 5 per cent. brine and the solution heated to $67^{\circ}$. The flocculent coagulum, which began to separate at $59^{\circ}$, was filtered out, washed and dried, giving 1.87 grams of F.3.I. The filtrate heated to $92^{\circ}$ gave another coagulum which began to separate at about $70^{\circ}$. This, when dry, weighed 2.I 7 grams, F.3.2. The filtrate from F.3.2 dialyzed free from chlorides and, precipitated by alcohol, gave 1.39 grams of F.3.3.

Twenty-five grams of K.3 (the more soluble part of a precipitate obtained by adding an equal volume of saturated ammonium sulphate solution to a large quantity of egg white) were dissolved in about $800 \mathrm{cc}$. of Io per cent. brine, the solution 


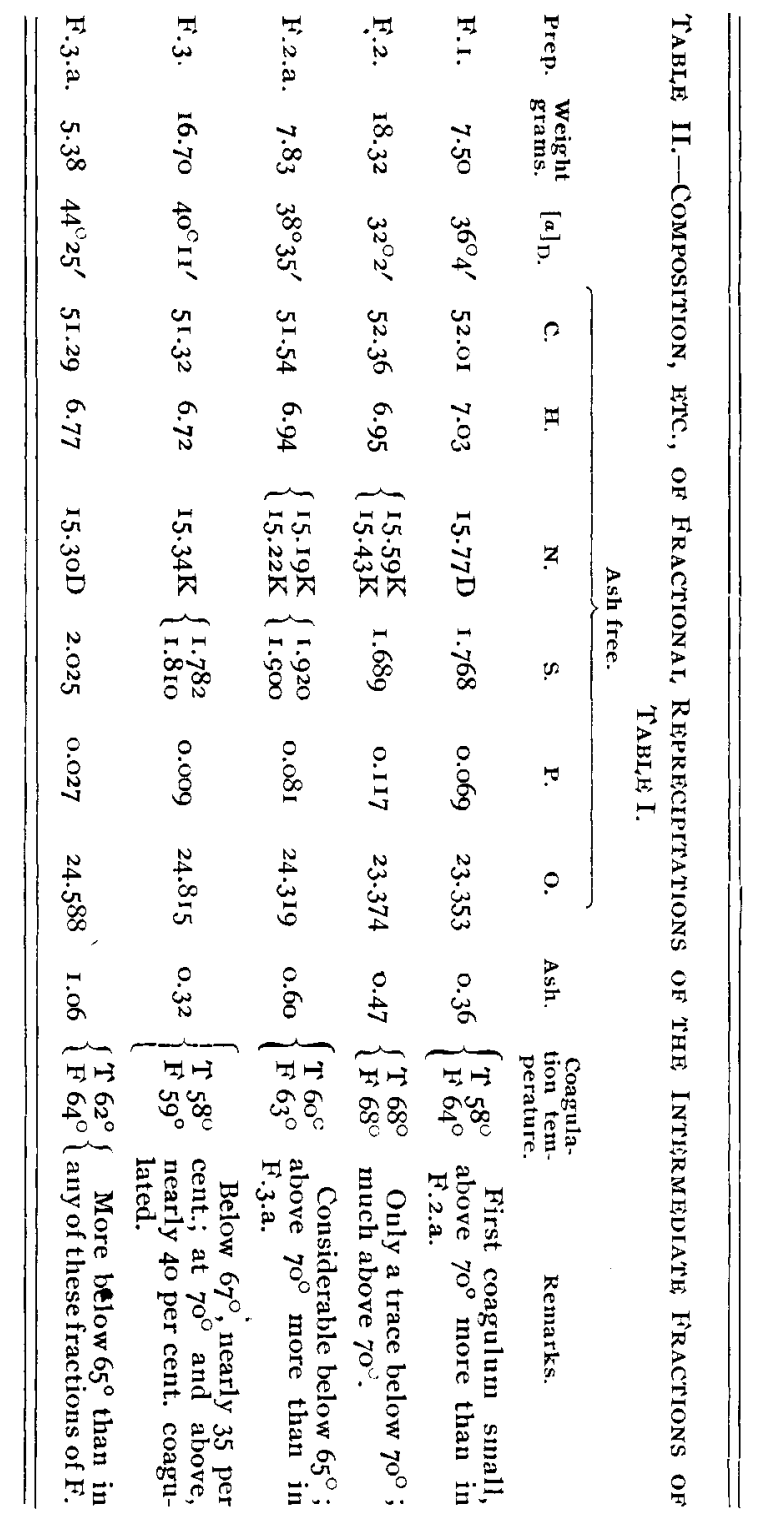


filtered clear and heated to $60^{\circ}$. The coagulum was washed with salt solution, suspended in water after passing through fine bolting-cloth to break up all lumps, washed thoroughly with water, and with alcohol, and was dried, giving 2.78 grams of K.3.I. Unlike ovalbumin, this coagulated proteid separated in a finely divided state, so that it could be easily washed through the cloth.

The filtrate from this coagulum was dialyzed free from chlorides and then evaporated to dryness below $60^{\circ}$, leaving a residue which weighed $\mathrm{i} 7.2$ grams and had a specific rotation of $37^{\circ} 55^{\prime}$. This rotation being much greater than that of ovalbumin, the whole of this residue was dissolved in Io per cent. brine, the solution heated in a boiling water-bath, the coagulum, K.3.2, filtered off, the filtrate dialyzed free from chloride, and the clear solution poured into alcohol. The substance, K.3.3, thus precipitated, weighed, dry, I.39 grams, and consisted of ovomucoid as shown by its rotation, $61^{\circ} 30^{\prime}$.

The preparation, K.3, was prepared from the precipitate produced by half saturating the egg white solution with ammonium sulphate, which precipitate is commonly supposed to consist aimost wholly of globulin. Nevertheless our results show that K. 3 contained about $\mathrm{I}$ I per cent. of the albumin coagulating below $65^{\circ}, 83$ per cent. of ovalbumin, and over 5 per cent. of ovomucoid. That so much of this latter substance should be present in this preparation is surprising and shows the difficulty in separating ovomucoid from ovalbumin.

All these preparations were analyzed with the results given in Table III.

These figures show that an albumin coagulating at $55^{\circ}-57^{\circ}$ forms nearly 50 per cent. of the products obtained from D.3. This albumin contains somewhat less carbon, decidedly more nitrogen, and a little more sulphur than ovalbumin. Since it so closely resembles ovalbumin, and is so intimately associated with it the writer suggests that it be called conalbumin. The rest of the products from D. 3 consists of about 35 per cent. ovalbumin and $\mathrm{I} 8$ per cent. ovomucoid. From F.3, 27 per cent. of conalbumin, 3 I per cent. of ovalbumin, and 20 per cent. of ovomucoid were obtained.

This investigation of the protein constituents of the egg white 


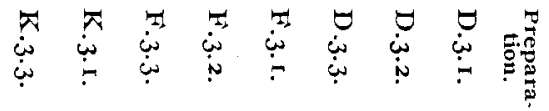

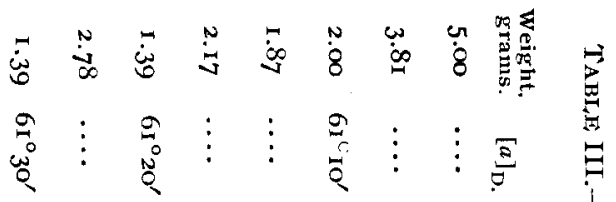

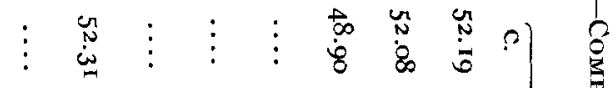

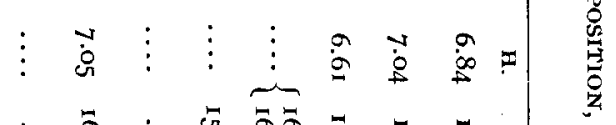

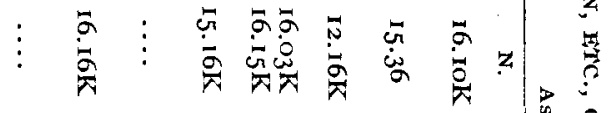

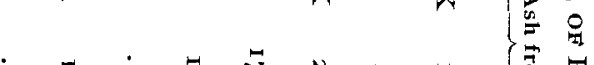

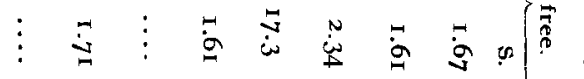

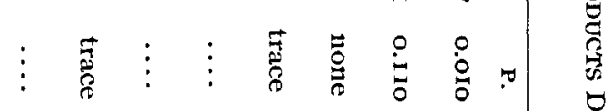

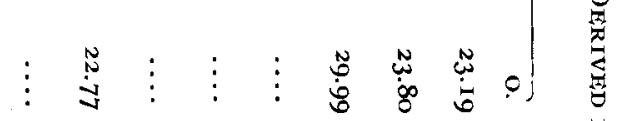

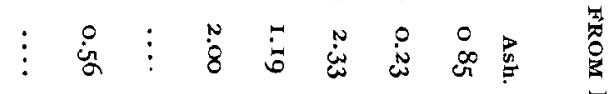

น

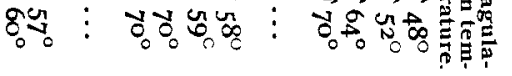

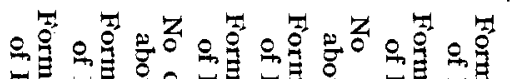

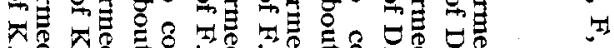

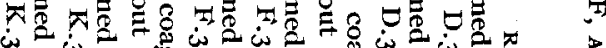

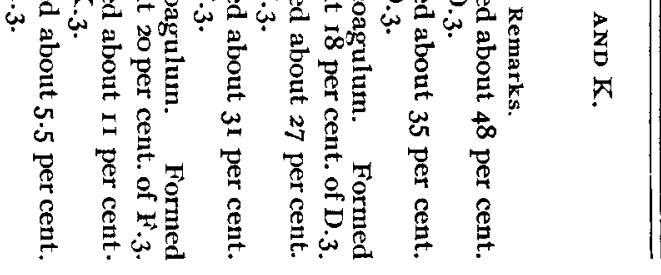


shows them to be ovomucin, ovalbumin, conalbumin, and ovomucoid. These have the following properties:

Ovomucin is a glycoproteid recently discovered by Eichholz ${ }^{3}$ to be present in small amount in egg white. This substance, precipitated by diluting egg white, has heretofore been regarded as globulin, but we find that nearly, if not quite, all of that which is so precipitated, is ovomucin.

From the whites of $240 \mathrm{eggs}$ we obtained, although with some loss, 34.2 grams of ovomucin or about 7 per cent. of the proteid matter of the egg white, which is the proportion in which Dillner found the "globulin" to be present.

When freshly precipitated by dilution or dialysis, ovomucin loses its gummy character on thoroughly washing with water, but, when treated with salt solutions, forms a transparent gummy mass, which, on agitation, yields a clear but viscid solution.

When washed with alcohol and dried, ovomucin forms a light, white powder, partly soluble in sodium chloride brine, and gives a solution free from viscidity, which becomes turbid at $75^{\circ}$, and yields flocks at $78^{\circ}$. Cn boiling, this coagulum almost wholly dissolves and reappears on cooling.

Eichholz states that ovomucin dissolves in dilute sodium carbonate solutions. We find, however, that when treated with much I per cent. sodium carbonate, only an apparent solution results, for, when this is brought into filters, a clear, thin liquid passes through the paper from which, by adding acid, only an insignificant precipitate can be obtained, while a clear and very viscid liquid, containing almost all the ovomucin, remains upon the paper.

We have made, page 423 , two preparations of ovomucin which had the following composition:

OVOMUCIN.

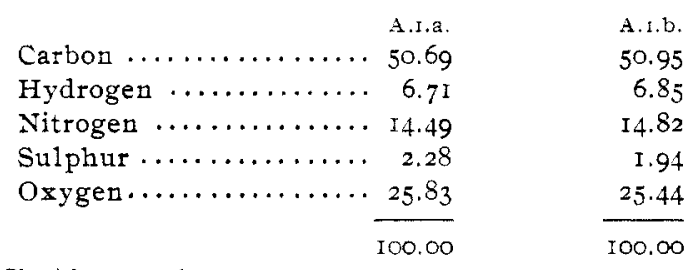

1 Jour. of Physiology, 33, 167.

A.i.b.

50.95

6.85

4.82

I. 94

25.44

100.00 
Ovalbumin is the chief constituent of egg white, 50 per cent. of its proteids having been obtained in this investigation in the form of perfectly crystallized preparations of this substance, while a large proportion of the remaining proteid matter also consisted of this albumin.

Heat Coagulum of Ovalbumin.-Solutions in pure water, containing 2.5 per cent. of pure ovalbumin, become turbid at $60^{\circ}$, and at $64^{\circ}$ yield a flocculent coagulum.

When ro per cent. of sodium chloride is added to these solutions the temperature of coagulation becomes higher, turbidity developing at $69^{\circ}$, and flocks at $70^{\circ}$.

When its solution is evaporated to dryness below $50^{\circ}$, and the ovalbumin redissolved in water or in brine, a small amount of substance coagulating at the lower temperature appears to be formed. Thus, sodium chloride solutions containing 2.5 per cent. of B.I, B.2, or C.I, before these substances had been separated by evaporation at $50^{\circ}$, remained absolutely clear until heated to $68^{\circ}$ or $69^{\circ}$, while similar solutions, made by dissolving the dried substance, became turbid at $59^{\circ}$ and yielded flocks in small quantity at $63^{\circ}$.

Preparations of ovalbumin obtained by evaporating their solutions in pure water to dryness below $50^{\circ}$, do not completely redissolve when treated with water.

Solutions of some preparations thus made, become very rapidly turbid when filtered and gradually deposit a not inconsiderable quantity of insoluble matter. The amount of insoluble matter in all of our preparations was so small, that we have been unable to learn its nature, but in one case we obtained 0.72 gram from I 5 grams of a preparation containing a larger proportion than any we had seen before. This insoluble substance, which contained 5.65 per cent. nitrogen, and 1.8 per cent. sulphur, was probably a mechanical coagulum, as it tended to separate at points of contact between the surface of the albumin solution and the vessel containing it. Sodium chloride added to the solution in sufficient quantity diminishes the amount, or prevents its formation. ${ }^{2}$

1 Stärke (Pfïger's Archiv, 12, 18) notes tbis effect of sodium chloride on the coagulation of the albumin.

2 See Hopkins: Jour. of Physiology, 25, 324. 
It has been stated by Hammarsten that with a constant amount of salt the temperature of coagulation changes with variable amounts of albumin in solution.

We, accordingly, prepared solutions of the dialyzed, but not dried, albumin which contained $5,2.5$, and 1 . o per cent. of ovalbumin and also similar solutions containing, in addition, to per cent. of sodium chloride. These, when heated rery slowly in a large water-bath, coagulated as follows:

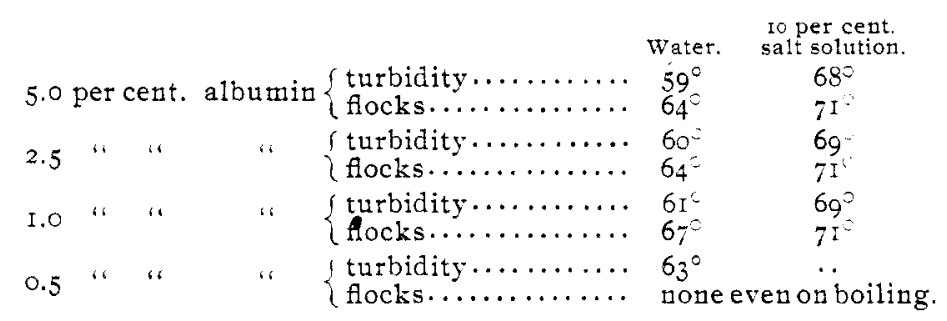

These figures show no difference in temperature of coagulation, for solutions containing from I to 5 per cent. of ovalbumin, together with Io per cent. of sodium chloride, but solutions of ovalbumin in pure water coagulate at a lower temperature than those containing ro per cent. of this salt; those containing 5 and 2.5 per cent. of albumin, coagulate at one and the same temperature; those containing I per cent. coagulate somewhat higher, while a solution containing but 0.5 per cent. of albumin yields no flocks even on boiling.

When the proportion of albumin remains constant, while that of the salt increases, the temperature of coagulation rises, as the following table shows:

\begin{tabular}{|c|c|}
\hline $\begin{array}{l}\text { NaCl. } \\
\text { Per cent. }\end{array}$ & $\begin{array}{l}\text { Ovalbumin } \\
\text { Per cent. }\end{array}$ \\
\hline 1,0 & 2.5 \\
\hline 3.0 & 2.5 \\
\hline 5.0 & 2.5 \\
\hline 10.0 & 2.5 \\
\hline
\end{tabular}

$\left\{\begin{array}{l}61^{\circ} \text { turbidity. } \\ 63^{\circ} \text { flocks. }\end{array}\right.$
$\left\{\begin{array}{l}63^{\circ} \text { turbidity. } \\ 65^{\circ} \text { flocks. }\end{array}\right.$
$\left\{\begin{array}{l}65^{\circ} \text { turbidity. } \\ 67^{\circ} \text { flocks. }\end{array}\right.$
$\left\{\begin{array}{l}68^{\circ} \text { turbidity } \\ 70^{\circ} \text { flocks. }\end{array}\right.$

From these results we may state that solutions in water which contain from 2.5 to 5 per cent. of pure ovalbumin become turbid on heating to $60^{\circ}$, and yield a Hocculent coagulum at $64^{\circ}$, 
while those containing, in addition, ro per cent. of sodium chloride become turbid at $68^{\circ}$, and flocculent at $70^{\circ}$.

In the preceding experiments no acid was added to the solution to be coagulated, the acidity of the ovalbumin (I gram of albumin required $2 \mathrm{cc}$. of $\mathrm{N} / \mathrm{ro}$ alkali for neutralization to pinenolphthalein) being sufficient to bring about coagulation.

When the albumin was exactly neutralized to phenolphthalein, by adding potash, the solution remained clear when heated for some time at $100^{\circ}$. When this solution was treated with acid equivalent to the added alkali a large precipitate resulted which did not separate completely until a very slight excess of acid was added. Thus, when 0.5 gram of albumin was dissolved in I9 cc. of water, I cc. N/Io potassium hydroxide added, making the solution exactly neutral to phenolphthalein, and the mixture heated for ten minutes in boiling water, no coagulum was produced. When cooled, I cc. of $\mathrm{N} / \mathrm{I}$ o hydrochloric acid was added, which gave a precipitate, from which a clear filtrate could not be obtained; with I.2 cc., however, the precipitation was so complete that the filtrate gave no turbidity with alcohol. When I gram of albumin was dissolved in water and $2 \mathrm{cc}$. of $\mathrm{N} / \mathrm{ro}$ ammonia solution were added, a quantity just sufficient to neutralize the acid reaction of the albumin, the solution remained clear after heating for some time at $100^{\circ}$. After cooling, on adding $\mathrm{N} / \mathrm{I}$ o hydrochloric acid, the solution remained clear until nearly enough acid had been added to neutralize the $2 \mathrm{cc}$. of ammonia, but when the full $2 \mathrm{cc}$. were added the albumin was so completely precipitated that the solution filtered from the coagulum contained only a trace of protein matter. The solution, thus neutralized with either potash or ammonia, gave off hydrogen sulphide when heated and acidified.

To six tubes, each containing 0.5 gram of albumin, dissolved in ro cc. of water, were added respectively $0.2,0.4,0.6,0.8, \mathrm{I}$, and I.I cc. N/Io hydrochloric acid, and then water enough to make each up to $20 \mathrm{cc}$. When these mixtures were heated in boiling water, the one with $0.8 \mathrm{cc}$. of acid yielded some coagulum, that with I cc. but a trace, while that with I.I cc. remained clear, showing I cc. of $\mathrm{N} / \mathrm{I}$ o hydrochloric acid to be enough to convert $0.5 \mathrm{gram}$ of albumin into a compound not coagulated by heat. The portions with 0.2 and $0.6 \mathrm{cc}$. were com- 
pletely, while that with $0.8 \mathrm{cc}$. was incompletely, coagulated. When 0.5 gram of albumin was dissolved in $20 \mathrm{cc}$. of water, containing from $0.5 \mathrm{cc}$. to $3 \mathrm{cc}$. of $\mathrm{N} / \mathrm{ro}$ acetic acid and heated in a boiling water-bath, the albumin was practically completely coagulated; with $5 \mathrm{cc}$. of acetic acid the solution becane opalescent at $64^{\circ}$, and formed a firm, transparent jelly at $75^{\circ}$. On heating at $99^{\circ}$ with Io cc. of N/ro acetic acid the solution formed a clear, thin jelly.

When solutions in pure water of any of our purest preparations of ovalbumin were heated to boiling for some time the albumin was so incompletely coagulated that a clear filtrate could not be obtained.

Six 2-gram portions of pure ovalbumin, were dissolved, each in too cc. of water, and mixed with equal volumes of water, containing $\mathrm{I}, 2,3,4,5$, and $6 \mathrm{cc}$. of $\mathrm{N} / 10$ acetic acid respectively, and the mixtures boiled and poured on filters. The portion with I cc. of acid clogged the filter, as the coagulum separated imperfectly, whereas the others yielded clear filtrates. These, when evaporated to dryness, left residues weighing $0.0492,0.0332$, $0.0320,0.0446$, and 0.0648 gram, respectively.

From this it is seen that with I cc. of $\mathrm{N} / \mathrm{IO}$ acetic acid the coagulation is incomplete, while with 3 and $4 \mathrm{cc}$. the amount of matter remaining in solution is less than with $2 \mathrm{cc}$. or than with 5 and $6 \mathrm{cc}$. This dissolved matter, which is very soluble in water, yields a solution decidedly acid to phenolphthalein and to litmus, contains proteid, and reduces Fehling's solution. Since the proportion, in which it is produced, appears to depend upon the quantity of acid added, we are inclined to regard it chiefly as a product of the action of the added acid upon a small part of the albumin, whereby uncoagulable acid compounds are formed in small, but variable proportion.

Specific Rotation.-This was determined for solutions of the ovalbumin in pure water, with a Schmidt and Haensch polarimeter, the readings of the sugar scale being converted into degrees of circular polarization by multiplying by 0.346 , and the amount of dissolved albumin ascertained by evaporating and drying the residue at $I 10^{\circ}$. Preparations B.I, B.2, C.I, and C. 2 showed very nearly the same rotation as that found by us in our 
former work for preparations of pure ovalbumin. These determinations gave the following values for $[\alpha]_{D}$.
A. $1^{1} \ldots \ldots \ldots \ldots \ldots-29.31^{\circ}$
B.r............ $-29.53^{\circ}$
A. $2^{1}, \ldots \ldots \ldots \ldots,-29.40^{\circ}$
B.2........... $-29.13^{\circ}$
H. $1^{1} \ldots \ldots \ldots \ldots,-28.60^{\circ}$
C.I............ $-30.03^{\circ}$
$\mathrm{H} .2^{1} \ldots \ldots \ldots \ldots,-29.8 \mathrm{I}^{\circ}$
C.2............ $-30.80^{\circ}$

The degree of rotation was found to be the same in sodium chloride solutions as in water, and also to be the same for the albumin in the dialyzed solutions of the crystals, as in solutions of the albumin which had been separated from such solutions by evaporation at $50^{\circ}$.

Since this paper was written we have received the number of the Journal of Physiology issued April 24, rgoo, containing a paper on "Pure Albumin", by F. G. Hopkins, in which be gives the rotary power of pure albumin as $-30.70^{\circ}$. The remarkable agreement between the rotation of the many fractional crystallizations, obtained by Hopkins, is much closer than between those observed by us, which is probably due to his superior polariscope and to the stronger solutions of the albumin, containing considerable amounts of ammonium sulphate, which he employed. Because solutions rich in pure albumin, when free from salts, are not easily obtained absolutely clear and tend to become turbid, probably from mechanical coagulation, we were generally not able to use solutions so rich in albumin as those employed by Hopkins. The difference of $1.3^{\circ}$ between the values of $[a]_{D}$ found by Hopkins and the writer, is probably chiefly due to the different methods employed for determining albumin in the solution examined. We have shown, page 438 , that when ovalbumin is coagulated in the presence of a minimum of acetic acid, about 1.5 per cent. of uncoagulated matter remains in solution. Whether this occurs under the conditions under which Hopkins coagulated his albumin requires further investigation. Hopkins admits that the method employed by us is the more accurate, assuming that all ammonium sulphate can be separated from the albumin solution. We believe that we have accomplished this in view of the great care we have taken to detect the presence of sulphates in our albumin preparations and feel quite sure that we have not overlooked a quantity of ammo-

1 These ate preparations of the old series formerly described, and the two fist are not parts of fraction $A$ of the present series. 
nium sulphate sufficient to have caused a difference of 4 per cent. of the observed rotation.

Elementary Composition. - In the following table we give the analyses of our four purest preparations of ovalbumin, and also analyses of two preparations made by Hofmeister's method as described on page $44 \mathrm{I}$.

COMPOSITION OF OTALBUMIN.

\begin{tabular}{|c|c|c|c|c|c|c|c|}
\hline Carbon...... & $\begin{array}{c}\text { B.I. } \\
52.59\end{array}$ & $\begin{array}{c}\text { B.2 } \\
52.78\end{array}$ & $\begin{array}{c}\text { C.I. } \\
52.75\end{array}$ & $\begin{array}{c}\text { C.2. } \\
52.79\end{array}$ & $\begin{array}{l}\text { No. } 2 . \\
52.82\end{array}$ & $\begin{array}{l}\text { No. } 3 \\
52.78\end{array}$ & $\begin{array}{l}\text { Aver- } \\
\text { age. } \\
52.75\end{array}$ \\
\hline Hydrogen... & 7.10 & 7.09 & $7 \cdot 3 \mathrm{I}$ & 7.00 & 7.03 & 7.07 & 7.10 \\
\hline Nitrogen.... & 15.55 & 15.57 & I 5.50 & I 5.60 & I 5.32 & I 5.53 & I5.5I \\
\hline Sulphur.... & $1.6 \mathrm{I}_{3}$ & 1.619 & $\mathrm{I}, 6 \mathrm{I} 3$ & 1.634 & $I .590$ & I. $65 \mathrm{I}$ & I. 620 \\
\hline Phosphorus . & 0.126 & 0.127 & $0.13 I$ & 0.126 & 0.123 & $0 . \mathrm{II} 2$ & 0.122 \\
\hline Oxygen ..... & 23.021 & $22.8 I 4$ & 22.696 & 22.850 & 23.117 & 22.857 & 22.898 \\
\hline & 000 & .000 & 000 & 00.000 & 0.000 & 00.000 & 100.000 \\
\hline
\end{tabular}

ANalitical Methods.

Carbon and hydrogen were determined by using an open tube with copper oxide, lead chromate, and metallic copper, and finishing the combustion in oxygen.

Nitrogen was determined by Dumas' method, the air being removed by a Sprengel pump, the tube then filled with carbon dioxide set free by heating sodium bicarbonate at the front end, again emptied by the pump and this process repeated. In this way all the air was removed and no fixed gas was driven off on heating the reagents. Nitrogen was also determined by the Kjeldahl method and results in close accord with those of Dumas' method were obtained.

Sulphur was determined by fusing about I gram of the substance with sodium hydroxide and peroside over an alcohol lamp. The reagents were proved to be free from sulphur.

Phosphorus was determined by fusing about I gram of the substance with sodium peroxide, dissolving the fusion in nitric acid, precipitating with molybdic solution and weighing as magnesium pyrophosphate.

The figures given in the above table agree well with those of others who have prepared and analyzed ovalbumin with especial care as may be seen in the following table:

\section{COMPOSITION OF OVAIBUMIN.}

\begin{tabular}{|c|c|c|c|c|c|c|c|}
\hline & c. & H. & N. & s. & P. & 0. & \\
\hline Hammarsten & 52.25 & 6.90 & 15.25 & I. 64 & $\ldots$ & 23.69 & uncoag. \\
\hline A Bolton & 52.33 & 6.98 & $I_{5} .89$ & $\mathrm{I} .8_{3}$ & $\ldots$ & 22.97 & \\
\hline “ & 52.33 & 6.98 & 15.84 & $1.8 \mathrm{I}$ & $\cdots$ & 23.04 & coag. \\
\hline Id Zoja & 52.39 & $7 \cdot \mathrm{II}$ & I 5.39 & I.66 & ... & 23.45 & \\
\hline Campbell.... & 52.75 & 7.10 & $\mathrm{I} 5.5 \mathrm{I}$ & 1.62 & 0.12 & 22.90 & \\
\hline Hopkins. . & 52.75 & 7.12 & I 5.43 & 1.57 & & & \\
\hline
\end{tabular}


There would be no longer any question about the composition of ovalbumin, were it not for Hofmeister's analysis of a single preparation, and the recent assertion of Schulz, ${ }^{2}$ that on crystallizing by the "acid process " a hydrate of Hofmeister's egg albumin is formed. This we have shown in our former paper to be untrue, for we there gave the results obtained by analyzing a preparation made exactly according to Hofmeister's method, which agreed quite well with the analyses of all our other preparations made by the acid method of Hopkins.

That there should be no question as to the composition of crystallized ovalbumin made according to Hofmeister's method we made preparation No. 2, recrystallized six times and coagulated by alcohol, No. 3, by recrystallizing four times, pressing the crystals on filter-paper, dissolving them in water, dialyzing the solution perfectly free from sulphate and evaporating the filtered solution at $50^{\circ}$ to dryness.

Dried at $110^{\circ}$ these preparations were found to have the following composition:

COMPOSition of OVALBUMiN CRYSTALIIZED BY HOFMEISTER'S METHOD.

\begin{tabular}{|c|c|c|c|}
\hline & No. 2. & No. 3. & $\begin{array}{c}\text { Average of the } \\
\text { analyses given } \\
\text { on page } 365 \text {. }\end{array}$ \\
\hline Carbon.............. & 52.82 & 52.78 & 52.75 \\
\hline Hydrogen ........... & 7.03 & 7.07 & 7.10 \\
\hline Nitrogen...$\ldots \ldots$ & $15 \cdot 32$ & 15.53 & $15 \cdot 5 \mathrm{I}$ \\
\hline Sulphur........... & 1.590 & 1.651 & 1.62 \\
\hline Phosphorus......... & 0.123 & 0.112 & 0.12 \\
\hline Oxygen...$\ldots \ldots \ldots$ & 23.117 & 22.857 & 22.90 \\
\hline & 100.000 & 100.000 & 100.000 \\
\hline
\end{tabular}

These analyses are in almost exact agreement with the average given in the preceding table, and fail to confirm Hofmeister's figures for sulphur, or the conclusions drawn by him and by Schulz respecting the relation of the crystallized albumin to that heretofore obtained by other methods. The percentage of carbon found by us falls midway between that given by Hofmeister and the average of that given by the other investigators, with the exception of Hopkins. The very close agreement in composition between all the many fractions, having a constant rotatory power, analyzed by Hopkins and by ourselves, leaves

1 Ztschr. physiol. Chem., 16, 187.

2 Ibid., 29, 86. 
little doubt as to the true elementary composition of crystallized ovalbumin, especially in view of the close agreement of these analyses with those of Hammarsten and of Bondzynski and Zoja.

In view of the statements recently made by Schulz concerning the proportion of sulphur in ovalbumin, 'we used the very greatest care in determining this element. Our solutions of albumin were not only dialyzed until they gave no reaction with barium chloride, but until no sulphate could be detected in the water outside of the dialyzer, even after concentration. That our higher figures for sulphur are not due to ammonium sulphate, which could not be separated from the albumin by dialysis, is disproved, not only by the close agreement between our many analyses, but also by the fact that we obtained exactly the same figures from preparations free from conalbumin and ovomucoid, made by coagulating their dilute solutions at $70^{\circ}-95^{\circ}$. Thus, we found in D.3.2, r.6I, in F. $2.1,1.64$, in F.3.2, 1.61 , and in E.3.a, 1.63 per cent. We have no doubt that these figures very closely represent the true proportion of sulphur contained in the ovalbumin, especially as they agree with the figures which Hammarsten obtained, " by four different methods; namely, I.67, I.67, I.62, and 1.58 and also with those of Bondzynski and Zoja. The results obtained by Hopkins, ${ }^{3}$ which have come to our notice since this paper was written, leave no doubt whatever that the true proportion of sulphur is very close to 1.60 per cent., Hopkins finding an average of 1.57 per cent. while we find 1.62 per cent., the slight difference between our results being doubtless due to slight differences in our methods of operation.

It is to be noted that we have found a small but uniform quantity of phosphons in all our preparations of crystallized albumin. In Table I, page 428 , it is seen that the four crystallized preparations, B.I, B.2, C.I, and C.2, all contained 0.12 per cent. of phosphorus, whereas all the other non-crystalline preparations contained less, the amount diminishing as the proportion of ovalbumin diminished in the successive fractions. In Table

\footnotetext{
1 Ztschr. physiol Chem., 25, I6:29,86

2 Ibid., $9,304$.

3 Jour, of Physiology, 25, 306.
} 
III, page 432 , it appears that D.3.I, consisting of conalbumin, contained but 0.0 I per cent., whereas D.3.2, consisting of coagulated ovalbumin, conțained 0. I I per cent., and D.3.3, consisting of ovomucoid, contained but a trace.

In our earlier series of preparations, this phosphorus was found in the ash, as calcium phosphate; in our present series, only a part of it was present in the ash, in which it occurred as sodium or potassium metaphosphate.

As our former series of preparations were dialyzed in river water containing calcium bicarbonate and our later series in distilled water, it seems highly probable that this phosphorus belongs to an acid united with the crystallized albumin in the same manner as the writer has shown that hydrochloric acid unites with edestin to form crystalline compounds. ${ }^{1}$

As to the nature of this phosphorized acid we have learned nothing, owing to the small proportion in which it is present.

THE CARBOHYDRATE SPLIT FROM THE OVALBUMIN BY BOIIING WITH ACIDS.

These purest preparations of ovalbumin, which we have shown to have a constant specific rotation, the same composition and the same temperature of coagulation, when boiled with acids, all give solutions which yield considerable quantities of crystalline precipitates with phenylhydrazine.

When boiled with 3 per cent. hydrochloric acid for thirty minutes, the solution obtained reduces Fehling's solution, but fails to do so after boiling for three hours. The addition of Fehling's reagent to such solutions causes an intense biuret reaction, but no reduction of the copper salt takes place, even after adding considerable quantities of glucose. Evidently, by continued boiling, some substance is produced which prevents the reduction of the Fehling's solution. Blumenthal and Mayer $^{2}$ state that after long boiling this reduction is not so easily detected as after boiling for a short time.

Ten grams of each of the four preparations, B.I, B.2, $\mathrm{CI}_{\text {I }}$ and C. 2, were boiled with $200 \mathrm{cc}$. of 9 per cent. sulphuric acid for three hours and the solutions neutralized to litmus with baryta. The soluble matter was filtered out, washed with water, and the filtrate

1 This Journal, 21, 486.

2 Ber. d. chem. Ges., $32,274$. 
and washings were evaporated to a volume of $100 \mathrm{cc}$. To this solution Io grams of sodium acetate were added and $5 \mathrm{cc}$, of a mixture of equal volumes of phenylhydrazine and 99 per cent. acetic acid, and the whole heated for three hours in boiling water. After standing over night, the crystalline precipitates were filtered off and washed rapidly with water and then with absolute alcohol, which removed a considerable quantity of deep red-colored, amorphous substance. The washed precipitates were then dried at $I \mathrm{IO}^{\circ}$ and weighed.

In order to learn the effect of the presence of ovomucoid, upon this precipitation with phenylhydrazine, Io grams of G.4, which had a specific rotation of $39^{\circ} 22^{\prime}$, and contained much ovomucoid, were treated in the same manner as these albumin preparations and at the same time with them.

For comparison, Ioo cc. of a solution containing I gram of glucose were treated with phenylhydrazine under the same conditions. The filtrate from each phenylhydrazine precipitate was further treated with $5 \mathrm{cc}$. of phenylhydrazine and ro grams of sodium acetate and a second precipitate obtained. From the filtrates from the second precipitations no more could be separated by further additions of phenylhydrazine. The weight of each precipitate dried at $11^{\circ}$, is given in the following table:

$$
\begin{aligned}
& \text { B.I. B.2. C.I. C.2. G.4. Glucose. } \\
& \text { Gram. Gram. Gram. Gram. Gram. Gram. }
\end{aligned}
$$

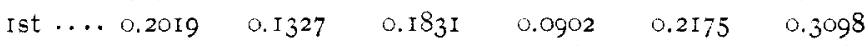

$$
\begin{aligned}
& \text { and } \cdots \frac{0.1030}{0.3049} \frac{0.1027}{0.2354} \quad \frac{0.0980}{0.2711} \quad \frac{0.0281}{0.1183} \quad \frac{0.2684}{0.4859} \quad \frac{0.3187}{0.6285}
\end{aligned}
$$

Since from C.2 we got so much less of this substance than from the others, we repeated this experiment, using for the first precipitation Io $\mathrm{cc}$. of the phenylhydrazine-acetic acid mixture and 20 grams of sodium acetate. In this way we got

C.2.

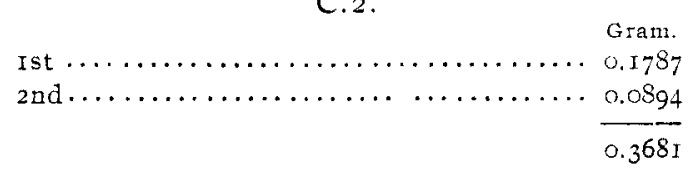

The crystals of the osazone obtained from the albuinin consisted of feathery sprays and always appeared distinctly differ- 
ent from the aggregates of needles yielded by glucose. Two different preparations of the phenylhydrazine compound were separately recrystallized by dissolving in boiling absolute alcohol, addin gwater, boiling until most of the alcohol had been expelled, and then allowing the solution to cool slowly until the substance separated in beautiful, yellow crystals of the same form as the original precipitate. These melted at $I 87^{\circ}$ and $I 89^{\circ}$.

The amount of this osazone indicates that a considerable quantity of carbohydrate is split from our albumin preparations by boiling with acids. The quantity of osazone which we obtained from our preparations varied from one-third to onehalf of that given by I gram of glucose under like conditions, and if the compound from the albumin is precipitated in the same proportion as the glucosazone we may infer that the albumin yields on hydrolysis from 3 to 5 per cent. of carbohydrate. The amount of osazone which we have actually obtained corresponds to from 2-2.5 per cent. of carbohydrate calculated as glucose. Hofmeister ${ }^{1}$ obtained from I gram of ovalbumin 0.13 gram of osazone, from which he infers the presence of 15 per cent. of carbohydrate.

Does this carbohydrate come from the ovalbumin or from a residue of ovomucoid which we have not separated by our fractional crystallizations? Seemann $n^{2}$ obtained a copper oxide reduction from ovomucoid corresponding to 34.9 per cent. of glucose. If this proportion is correct, we must have at least 6 per cent. of ovomucoid in our albumin preparations, to account for the minimum yield of osazone, corresponding to 2 per cent. of carbohydrate. This is probably the least quantity of ovomucoid which could yield this quantity of osazone. From the incompleteness of precipitation of osazone, it is probable that the quantity of ovomucoid would have to be more than twice as great to yield the quantity of osazone found. From G.4, which had a specific rotation of $39^{\circ} 22^{\prime}$, we obtained nearly twice as much osazone as from the ovalbumin, due unquestionably to the presence of ovomucoid in this preparation. If this increased yield of osazone is attended by an increase of $10^{\circ}$ in the rotation, an admixture of ovomucoid sufficient to yield such quantities of

1 Ztschr. physiol. Chem., 24, I70.

2 Archiv. f. Verdaungskrankheit, 4, 275. 
osazone would manifest itself by variations in the rotation of these albumin preparations, it being improbable that so much ovomucoid was admixed in uniform proportion in the successive crystallized precipitates. We have shown on page 438 that the preparations of ovalbumin when coagulated by heat, left in solution a small quantity of uncoagulable matter amounting to about I.6 per cent. of the albumin, the nature of which we have been unable to discover, owing to its small quantity. It may be ovomucoid, since it contains proteid matter and yields a copper-reducing body on boiling with acids, but in general appearance and manner of dissolving it does not behave like ovomucoid. As already stated on page 439, we think it more probable that this substance is a product of the action of acetic acid, whereby a small quantity of uncoagulable acid compounds of the albumin is formed. Hydrochloric acid, added in the same proportion as acetic acid, converts, in the absence of soluble salts, nearly all of the albumin into such uncoagulable compounds. A somewhat greater quantity of acetic acid does the same, entirely preventing coagulation. We therefore feel almost certain that the carbohydrate does not originate in admixed oromucoid, but is derived from the substance constituting the crystallized ovalbumin.

This belief is strengthened by the fact that, so far as we know, all but two of the several investigators who have thus examined coagulated egg albumin, have found evidence of the presence of considerable quantities of carbohydrates among its hydrolytic decomposition products, although most of them have endeavored to separate every trace of ovomucoid. Spencer, ${ }^{\text {' who failed to }}$ find carbohydrate, boiled his coagulated albumin for several hours with weak potash and then for thirty minutes with io per cent. potash, a procedure which might lead to the destruction of carbohydrate. Moerner ${ }^{2}$ who also found no carbohydrate, gives no account of the method he used in preparing the ovalbumin.

Hammarsten regards crystallized ovalbumin as a glycoproteid and considers the carbohydrate group to be a constituent of a non-proteid substance combined with the protein substance proper.

1 Zischr, physiol. Chem., 24, 354.

2 Centrbl. Physiol., 7. 
This is certainly true of the nucleoproteid of the pancreas from which Bang obtained guanylic acid, which on hydrolysis yielded about 30 per cent. of carbohydrate. The mucins also appear to be compounds of protein matter with sugar-yielding substances.

We have stated our belief that crystallized ovalbumin is a compound of some acid wich protein substance and consider it quite probable that this acid contains the carbohydrate group.

We have been unable to obtain any evidence of carbohydrate in edestin, the crystallized globulin of hemp-seed, nor, according to Hammarsten, can a carbohydrate be split from casein, vitellin, myosin, and fibrinogen. This subject requires further careful study before a definite conclusion can be reached. At present the preponderance of evidence indicates that the carbohydrate is not derived from the protein molecule, but from substances combined with the protein as it is obtained from the tissues or secretions.

Conalbumin.-Our fractions of the proteids of egg white obtained after separating the crystallized fractions, all have a higher rotation and sulphur content and a lower temperature of coagulation than ovalbumin, as is shown in Table I. In Table III we showed that these fractions could be separated into two products by heating their solutions to $65^{\circ}$, filtering off the coagulum, and then heating the filtrate to $90^{\circ}$. In the filtrate from this latter coagulum a substance remained which was not coagulated by boiling.

The body coagulating at the lower temperature we designate conalbumin, on account of its close relation in properties and composition to ovalbumin. What this relation may be, we have not determined. Conalbumin and ovalbumin may be different compounds of the same protein, or the former may be a derivative of the latter involving a molecular change.

Composition of Coagulated Conalbumin.

\begin{tabular}{|c|c|c|c|c|c|c|c|}
\hline & \multicolumn{2}{|c|}{ D.3.1. } & \multicolumn{2}{|c|}{ F.3.1. } & \multicolumn{2}{|c|}{ K.3.1. } & \multirow[t]{2}{*}{ Average. } \\
\hline & I. & II. & I. & II. & I. & II. & \\
\hline Carbon: & 52.17 & 52.20 & $\cdots$ & $\cdots$ & 52.47 & 52.14 & 52.2 \\
\hline Hydrogen ... & 6.98 & 6.70 & $\ldots$ & $\ldots$ & 7.02 & 7.09 & $6 . c$ \\
\hline Nitrogen .... & 16.04 & I6.I6 & 16.03 & 16.15 & I6.16 & $\ldots$ & I6. II \\
\hline Sulphur.... & 1.67 & $\cdots$ & I. 73 & $\cdots$ & $1.7 \mathrm{I}$ & $\cdots \cdot$ & I. 70 \\
\hline Oxygen ...... & 23.14 & $\cdots$ & $\cdots$ & $\cdots$ & 22.64 & $\cdots$ & 22.95 \\
\hline & .00 & & & & 100.00 & & 00.00 \\
\hline
\end{tabular}


These figures show very little difference in composition between ovalbumin and conalbumin, the carbon being about 0.5 per cent. lower, the nitrogen about 0.53 per cent. and the sulphur 0.08 per cent. higher.

It is possible that the higher sulphur is due to a little ovomucoid carried down with the coagulum, but this is hardly probable, as the ovalbumin coagulated in the filtrates from these preparations contained $\mathrm{I} .6 \mathrm{I}$ per cent. of sulphur, which is exactly the quantity found in the most thoroughly purified preparations of ovalbumin.

Temperature of Coagulation. - When a solution of conalbumin is heated sufficiently, a finely divided flocculent coagulum separates which is very different from the dense masses that form in a similar solution of ovalbumin. As we could not separate the conalbumin from the other associated proteids except by coagulation, the temperature of coagulation of this albumin could not be determined under definite conditions. The temperature at which this substance begins to coagulate is influenced by the proportion of salts present. From a solution containing io per cent. of sodium chloride it separates at a lower temperature than from solutions in pure water. From the former solutions it apparently separated completely below $60^{\circ}$, whereas from the latter it is impossible to separate it from the ovalbumin because the latter begins to coagulate before the separation of the conalbumin is complete.

From solutions containing io per cent. of sodium chloride the preparations D.3. I and K.3. I separated below $60^{\circ}$, the solutions becoming turbid at about $55^{\circ}$. When 2.5 per cent. of K.3, D.3. and F.3 were each dissolved in Io per cent. brine their solutions became turbid at $57^{\circ}, 52^{\circ}$, and $58^{\circ}$, and flocks separated at $58^{\circ}$, $55^{\circ}$, and $59^{\circ}$, respectively.

Specific Rotation. - This we were unable to determine directly but indirectly the following results were obtained: of F.I, I.5 grams were dissolved in Io per cent. brine, the solution heated to $65^{\circ}$, and the coagulum filtered out and washed. The filtrate was heated to $98^{\circ}$ and the coagulum also filtered out and washed. The nitrogen was then determined in each coagulum and in the final filtrate, and the proportion of conalbumin, calculated on the dry preparation, was found to be 25 per cent; of ovalbumin 
62.7 per cent; and of ovomucoid 12.2 per cent. Subtracting the amount of rotation due to the sums of the two latter from the total rotation of $F$.I, we found the amount of rotation caused by the 25 per cent. of conalbumin, which for roo per cent. was equal to $[\alpha]_{D}-39^{\circ}$.

In the same way we found F.3 to contain 36.6 per cent. of conalbumin, 39.7 per cent. of ovalbumin, and 23.7 per cent. of ovomucoid, from which we calculated for the conalbumin $[\alpha]_{D}-36^{\circ}$. F.2.a contained 30.9 per cent. conalbumin, 48.9 per cent. ovalbumin, and 20.4 per cent. ovomucoid, so that in this preparation we found $[\alpha]_{D}$ equal to $-36^{\circ} 2 I^{\prime}$.

Of course such determinations cannot be accepted as final but they are sufficiently accurate to show that conalbumin has a different specific rotation from ovalbumin and is therefore a different substance. This conalbumin appears to be identical with albumin II, described by Panormoff,' infer from this abstract of his original paper ${ }^{2}$ the substance which he describes under this designation corresponds very closely with our fractions C.3, D.I, D.2, and D.3, whose mean rotation and other properties are the same as those given for albumin II.

These fractions we have shown to be mixtures of ovalbumin, conalbumin, and ovomucoid.

Ovomucoid.-After separating all the proteids coagulable by heat, Neumeister ${ }^{3}$ found in the white of eggs a substance which he called pseudopeptone. Later Möruer ${ }^{4}$ showed this to be a glycoproteid and named it ovomucoid, under which name it is now generally known.

In Table $I$ it is to be noticed that all the fractions following those of the crystallized ovalbumin show an increasing value for $[\alpha]_{D}$ and proportional thereto an increasingly greater content of sulphur. This is chiefly due to ovomucoid associated with these fractions. In connection with the detection of sugar in the albumin molecule, it is important to recognize the difficulty with which ovomucoid can be separated from ovalbumin by fractional precipitation with ammonium sulphate.

As we have just shown, fraction F. I contained I 2.2 per cent.,

1 Chem. Centrbl., II, 487 ( 1898 ).

2 Jour, russ. phys. chem. Ges., 30, 302.

3 Ztschr. Biol., N. F., 9, 369 (I890).

4 Ztschr.physiol. Chem., 18, 525 (1893). 
F.3, 23.7 per cent., and F.2.a, 20.4 per cent. of ovomucoid. These fractions were obtained from those immediately following the separation of the crystalline ovalbumin, and F.I was precipitated by simply adding an equal volume of saturated ammonium sulphate solution to the solution of these fractions.

We have obtained two preparations of ovomucoid in sufficient quantity for analysis and have found them, when dried at $110^{\circ}$, to have the following composition, which agrees with that given by Zanetti ${ }^{1}$ and by Mörner ${ }^{2}$.

CoMposition OF OVOMUCOID.

\begin{tabular}{|c|c|c|c|c|c|}
\hline Carbon........ & $\begin{array}{c}E .4 \\
49.02\end{array}$ & $\begin{array}{l}\text { D. } 3.3 . \\
48.90\end{array}$ & $\begin{array}{c}\text { Zanetti. } 1 \\
48.94\end{array}$ & 48.75 & $\begin{array}{c}\text { Motuet } 2 \\
\ldots \ldots\end{array}$ \\
\hline Hydrogen ....... & 6.45 & $6.6 \mathrm{I}$ & 6.94 & 6.90 & $\ldots$ \\
\hline Nitrogen...$\ldots \ldots$ & $12.7 \mathrm{I}$ & 22.16 & 12.46 & $\cdots$ & $\mathrm{I} 2.65$ \\
\hline Sulphur ........ & 2.38 & 2.34 & 2.22 & $\ldots$ & 2.20 \\
\hline Oxygen .......... & 29.44 & 29.99 & 29.44 & $\cdots$ & $\cdots$ \\
\hline & & $\infty 0$ & $\infty$ & & \\
\hline
\end{tabular}

The specific rotation was found to be E.4, $-6 I^{\circ} 38^{\prime} ;$ D.3.3, $-6 \mathrm{I}^{\circ} \mathrm{IO}^{\prime} ; \mathrm{F} \cdot 3 \cdot 3,-6 \mathrm{I}^{\circ} 2 \mathrm{O}^{\prime} ; \mathrm{K} \cdot 3 \cdot 3,-6 \mathrm{I}^{\circ} 3 \mathrm{O}^{\prime}$.

\section{NOTE.}

The Employment of Ammonium Molybdate as a Test for Tin. -In the April number of this Journal there is a note by $\mathrm{Mr}$. Allen Rogers on the use of ammonium molybdate as "a very delicate test for tin." Mr. Rogers does not refer to my paper on this subject in the Chemical New's for December 15 last, ${ }^{3}$ and I shall therefore assume that he has not seen it. Perhaps I may therefore be permitted to state briefly the substance of that paper.

Although the color reaction involved is a well-known test for molybdenum, I have been unable to find that, prior to the appearance of my paper, it had ever been suggested as a test for tin; and, having regard to its extreme delicacy in this respect, it seems highly improbable if it had been, that the fact would have been allowed to go into oblivion. My own experience, and I

\footnotetext{
1 Ann. di Chim. e Farmac., No. 12, 1897 .

2 Zeit. physiol. Chem., 18, 525 .

3 Chem. News, 79, 282 (1899).
} 